\title{
A DIMENSÃO TERRITORIAL NAS FORMAÇÕES SOCIAIS LATINOAMERICANAS
}

\author{
Antonio Carlos Robert Moraes ${ }^{(*)}$
}

$\mathrm{O}$ apelo à espacialidade, vista como mediação particularizadora ${ }^{1}$, adquire respaldo ontológico no estudo da história da América Latina, quando acatamos a centralidade dessa dimensão no objetivar-se dos processos de colonização. Tomemos, pois, a formação do sistema colonial moderno - e a construção da América principalmente - como, antes de mais nada, um processo interessando a relação sociedade/espaço. Disto deriva que é no apetite territorial de certas sociedades européias que devemos buscar o móvel primeiro da expansão marítima efetuada no "longo" século XVI². E é igualmente na capacidade plástica de se apropriar de lugares os mais diversos e moldá-los segundo seus interesses, que se pode avaliar o êxito ou fracasso dos vários empreendimentos coloniais.

Partimos, assim, da constatação inicial de que qualquer colônia é o resultado de uma conquista territorial. Ela é um espaço novo. na perspectiva do colonizador ${ }^{3}$. Um espaço ganho da natureza, de outros povos e de outros Estados. Uma adição de terras ao fundo territorial sob sua soberania. Por isso a determinação básica da colônia é a conquista, entendida aqui como uma relação específica entre uma sociedade que se expande e as pessoas, recursos e áreas dos lugares onde se exercita essa expansão. A violência e a expropriação são assim dados irredutíveis desse processo, variando em grau mas sempre presentes em suas manifestaçōes. Colonização implica assim, antes de mais nada, numa hierarquia entre sociedades e entre lugares ${ }^{4}$.

Observamos então que a formação colonial expressa, já em sua gênese, uma qualidade de subordinação. Ela é um resultado de uma ação que lhe é externa. Pois a colônia é, não um domínio abstrato (formal), mas a efetiva instalação do colonizador - a objetivação da conquista. As novas terras só são assim designadas para aqueles que chegam, obviamente não o são para as populações autóctones. Estas também aparecem, aos olhos do colonizador como verdadeiros atributos do lugar, que devem ser submetidos como parte da natureza a ser ganha. E a subordinação primeira necessária ao se instalar é, exatamente, a dos naturais. E, em função disso, os quadros demográficos defrontados vão constituirse no elemento básico para se entender a forma da instalaçāo e o arranjo gerado em cada caso ${ }^{5}$.

Vale observamos que existem objetivos comuns aos centros difusores, móveis metropolitanos animados pela dinâmica da transição que, em essência, perseguem a remuneração do capital comercial, isto é, o lucro mercantil ${ }^{6}$. Todavia, o tônus mercantilista se objetiva através de combinaçōes de interesses amarrados em quadros estatais nacionais. Tal arranjo redunda em projetos próprios a cada Estado, num quadro internacional pensado em termos essencialmente bélicos ${ }^{7}$. Isso se explicita em diferentes geopolíticas ultramarinas. Estas, por sua vez, exercitam-se em meio a realidades também variadas. Os territórios coloniais são erigidos na plasticidade dessa interfácie. Os desígnios geopolíticos metropolitanos devem se aplastar com o defrontado, tendo na adaptabilidade um elemento de eficiência.

(*) Professor Doutor do Departamento de Geografia da Faculdade de Filosofia, Letras e Ciências Humanas/USP

(1) Sobre este tema, ver: Wanderley Messias da Costa - "O Espaço como Categoria de Análise".

(2) Essa discussão pode ser encontrada em: Antonio Carlos Robert Moraes - Bases da Formação Territorial do Brasil. O territóró colonial brasileiro no "longo" século XVI, 1a. parte "Europa".

(3) Um bnm conjunto de estudos monográficos acerca dessa temática aparece em: Alvaro Jara et.alli - Tierras Nuevas, Expansión territorial y ocupación del suelo en América (siglos XVI-XIX).

(4) A teorização de fundo que sustenta nossa reflexão emana das formulações de Milton Santos, sintetizadas em Por uma Geografia Nova. Especificamente sobre o tema em foco, ver desse autor: "Relaçōes Espaço-temporais no Mundo Subdesenvolvido" e "Espaço e Sociedade: a Formação econômico-social como teoria e como método". "América".

(5) Ver: Antonio Carlos Robert Moraes - Ob.cit., 3a. parte

(6) Sobre a logica própria a essa forma de capital, pode-se consultar o sugestivo trabalho de Peter Kriedte - Feudalismo Tardío y Capital Mercantii.

(7) Vale lembrar a observação đe Perry Anderson de que, no período considerado, "A guerra não era o desporto dos príncipes, era seu destino" (Linhagens do Estado Absolutista, p. 33). 
Se acatamos este raciocínio, de imediato fica difícil equacionar a realidade colonial numa ótica que trabalhe com a oposição interno/externo. Pois - repetimos - a colônia é, em si, a instalação do agente externo, sua internalização na nova terra, através da conquista dos lugares e da subordinação dos antigos ocupantes. Assim, sem submeter a população encontrada não há colonização, fato que coloca - por exemplo - várias feitorias seiscentistas portuguesas na Ásia fora da economia mundo capitalista ${ }^{\mathbf{8}}$. O estabelecimento de uma colônia implica necessariamente em domínio da terra - soberania - e esta é impossível sem algum nível de submissão de seus primitivos habitantes.

Nesses termos, a eliminação e/ou apropriação das populaçōes autóctones não pode ser avaliada como um aspecto a mais da expansão colonial mercantilista, pois está em seu centro. O recurso a uma das duas alternativas apresentadas repousará, em muito, na reação indígena ante ao conquistador'. Porém, a submissão efetiva se impõe a todos os casos, independente do nível político-cultural ou do efetivo demográfico de cada sociedade conquistada. Essa variedade vai influir, isto sim, e muito, na forma de exploração desenvolvida em cada rincão.

No que tange à vida econômica entabulada pelo colonizador, fato que já pressupõe certa perenidade da instalação (logo, um relativo êxito da conquista), dois vetores emergem com relevância na explicação dos vários resultados. Um está nas características do povo submetido, outro nos atrativos e riquezas defrontadas. Como visto, a densidade populacional e a organizaçăo social da população encontrada atuou fortemente nas formas de assentamento europeu no Novo Mundo. Nas zonas de maior concentraçāo (logo com uma divisão do trabalho mais complexa), o conquistador se depara com territórios formados (com hierarquías locacionais e circuitos definidos), e a obra colonizadora se traduz inicialmente na apropriação dessas estruturas preexistentes ${ }^{10}$. Nas áreas de população menos adensada e divididas em unidades políticas menores, a colonização se efetiva na destruição direta dos gêneros de vida tradicionais e no redirecionamento da força laborial indígena ${ }^{11}$. Nos dois casos, o controle dos habitantes é a chave da conquista.

Entretanto, não apenas o quadro demográfico atua sobre o assentamento. Igualmente a perspectiva de lucratividade do empreendimento nas novas terras in- flui na velocidade e profundidade do processo de instalação. Certos atrativos naturais, como a existência de jazidas de metais preciosos, elegem determinados sítios e imprimem direções a esse processo. Vale lembrar que a extração da prata e o abastecimento da zonas mineiras criaram novos circuitos e assentamentos, que inclusive envolveram amplos deslocamentos de populações. Assim, foram povoadas áreas naturalmente desfavoráveis como habitats humanos. O que pode revelar certa primazia desse vetor em relação ao anteriormente mencionado. Enfim, a força do valor contido (o valor do espaço) revela-se tanto na riqueza natural depositada, quanto no trabalho morto acumulado in situ ${ }^{12}$. E, ainda, no contingente humano estacionado em cada lugar. $O$ espaço do colonizador contém recursos, heranças e pessoas - são os vetores da atração.

Se por um lado, a perspectiva de lucro antevista comanda o assentamento do colonizador, por outro, o efetivo estabelecimento da produção (seja ela qual for: extrativa, agrícola, mineradora, etc.) só ocorre com a disponibilidade do fator trabalho. É ele a mediação inelutável entre a riqueza potencial e a mercadoria, o "espólio privilegiado da conquista" segundo expressão de Pierre Chaunu ${ }^{13}$. Portanto, a intenção do lucro só se faz potência com o acesso a estoques de força de trabalho. Nesse sentido, a produção de um território colonial, notadamente onde o colonizador não se defronta com estruturas produtivas sólidas preexistentes, implica uma faceta de povoamento. O tipo de povoador, seria

(8) Nesse sentido acatamos a distinção estabelecida por Wallerstein entre "periferia" e "arena exterior" na montagem da economia-mundo capitalista (ver: El Moderno Sistema Mundial, v.1). E também a orientação de Fernando Novais que deixa fora do processo de colonização as meras açōes de pilhagem e intercâmbio comercial (Ver: "Colonização e Sistema Colonial: Discussão de Conceitos e Perspectiva Histórica").

(9) Ver: J. Lafaye - Los Conquistadores e R. Romano-Mecanismos da Conquista Colonial.

(10) Para exemplificar com o império asteca, ver: A. René Barbosa-Ramirez - La Estructura Económica de la Nueva Espanha (1519-1810).

(11) Aqui, vale lembrar a estratégia do aldeamento missionário nas zonas de fronteira da colonização. Ver, por exemplo: Mariano Useche Losada - El Proceso Colonial en el Alto Orinoco-Rio Negro (Siglos XVI a XVIII).

(12) Sobre estes conceitos, ver: Antonio Carlos Robert Moraes e Wanderley Messias da Costa - Geografia Crítica: A Valorização do Espaço.

(13) Conquista e Exploração dos Novos Mundos (Século XVI), p. 243. 
fácil demonstrar, variou bastante no caso americano, assim como variaram as relações de trabalho a que estes estavam submetidos. Contudo, mecanismos de coerção extraeconômicos eram comuns às várias formas, tornando o trabalho compulsório um traço unificador ante a diversidade das formações coloniais americanas.

Assim, a valorização colonial do espaço tem no controle do fator trabalho um elemento nodal. As diferentes formas de que se reveste a coerção não deve enturvar a recorrência e centralidade dessa determinação. Nesse entendimento o escravismo vai aparecer como modalidade ${ }^{14}$. Desse modo, o povoamento colonial (estrito senso) é, em sua maior parte, um fluxo migratório forçado. Seja o servo sob contrato branco (aprisionado, comprado ou raptado na Europa), seja o escravo africano, seja ainda o índio (aldeado ou escravizado), todos pertencem a populações deslocadas de seu habitat originário e submetidas a um novo ordenamento social e espacial, que as qualifica através de mecanismo de exclusão como os impedimentos raciais e a seletividade territorial ${ }^{15}$.

A fixação dessas populações obedece, obviamente, à localização das unidades produtivas e esta é comandada pela taxa de remuneração do capital investido em cada lugar ${ }^{16}$. Aí, onde a lucratividade compense o gasto todos os obstáculos à instalação seráo superados, como bem o demonstra a aglomeração humana no estéril e insalubre sítio do cerro de Potosi ${ }^{17}$. Onde a inexistência de braços conviveu com grandes atrativos naturais, a mobilidade da força de trabalho compulsoriamente deslocada preencheu esse requisito. $\mathrm{O}$ que reforça o caráter modal do escravismo. Enfim, o dado locacional que comanda a atraçāo é, sem dúvida, a produtividade natural dos lugares em face dos interesses da economia mercantil da época.

Essa tônica exportadora do colonialismo em geral, e do seiscentista com maior ênfase ${ }^{18}$, acarreta um padrão de instalação com um claro sentido exomorfo. Isto é, os assentamentos se fazem, mesmo quando bastante interiorizados, articulados numa rede de circulação que demanda um porto, o qual engata as diferentes unidades produtivas com os circuitos atlânticos, os da realização de seus produtos. A subordinação desenhase assim com clareza no ordenamento espacial, no estabelecimento daquele padrão que Bernard Kaiser denominou de bacia de drenagem. A riqueza produzida nas colônias escoa por esses circuitos que têm nos desníveis de preços, entre a América e a Europa, o seu princípio-motor ${ }^{19}$.

O sistema colonial implica um formidável mecanismo de transferência geográfica do valor. A parcela do valor produzido fixada na colônia restringe-se, geralmente, ao mínimo necessário para tocar a vida econômica, política e cultural. O valor se fixa, por exemplo, como engenho, como fortificação, e como catedral. Todavia, é esse cabedal acumulado que define, em muito, o destino das diferentes colônias quando das conjunturas de retração do comércio mundial na "crise" do século $\mathrm{XVII}^{20}$. Diferentes saídas, de maior ou menor estruturação autárquica, definem como as várias colônias americanas vão vivenciar os rearranjos no cenário metropolitano.

A valorização colonial do espaço, apesar de objetivar um padrão voltado para fora, avança internamente num movimento de forte caráter extensivo. Isto é, a riqueza gerada repousa diretamente na magnitude do espaço apropriado, tal fato sendo válido tanto para o avanço areolar da fronteira agrícola e pecuária, quanto para a dilatação das zonas de transito onde se encontram as "riquezas do sertão" (os índios, os metais pre-

(14) Postura que tem importantes desdobramentos no debate sobre a caracterização do modo de produção vigente nas colônias americanas.

(15) Sobre a estruturação social das colônias, ver: Sedi Hirano: Pré-capitalismo e Capitalismo.

(16) Vale lembrar a teorização de Antonio Barros de Castro acerca do papel da renda diferencial na hierarquização das áreas de adensamento dos escravos africanos na América, ver: "As Māos e os Pés do Senhor de Engenho: a Dinâmica do Escravismo Colonial".

(17) Como observa Bartolomé Bennassar: "Uma enorme concentração urbana a 4 mil metros de altitude, numa paisagem estéril, só se explica pela existência da prata" (La América Española y la América Portuguesa, Siglos XVI-XVIII, p. 217). Este autor lembra que Potosí atinge a cifra de 150 mil habitantes em 1611, quando Sevilha - a maior cidade da Espanha - conta com apenas 100 mil.

(18) Eric Hobsbawm pontua bem a distinçăo do "novo tipo de colonialismo" do século XVII, exatamente no fato deste relevar - ao contrário do seiscentista - o "mercado colonial" ("A Crise Geral da Economia Européia no Século XVI", p. 115).

(19) Como bem o demonstra Pierre Vilar - Ouro e Moeda na História (1450-1920).

(20) Uma visão de síntese das variadas respostas locais americanas a esse processo mundial pode ser obtida na coletânea: Enrique Florescano (org.) - Haciendas, Latifundios y Plantaciones en América Latina. 
ciosos e as especiarias). Por isso, o móvel da conquista não se restringe ao período inicial da instalação, mas permanece como motor constante do dinamismo interno das formações territoriais coloniais.

$\mathrm{O}$ imenso fundo territorial da colônias americanas, aparentemente inesgotável nas perspectivas dos colonos e dos Estados metropolitanos, leva a que o mercado fundiário demore para aí se efetivar. É somente quando a margem de cultivo começa a decair (em função da distância e da produtividade dos solos) que algumas áreas de altíssima favorabilidade (e mesmo assim restritas a certas localizaçōes e a certos setores econômicos) adquirem um valor mercantil. Assim, durante largo tempo, a terra não é mercadoria na colônia, repousando no controle da mão-de-obra o meio de sua obtenção. Podemos dizer que, dum ponto de vista genérico, a existência de fundos territoriais atravessou todo o período colonial americano. $\mathrm{E}$, havendo terra a ser apropriada, havia conquista. E, havendo conquista, a dimensão espacial vem ao centro da estruturação da vida social.

Sintetizando, a valorização colonial do espaço necessita de agentes "passivos" (submetidos) que se amoldem aos interesses do sujeito colonizador, que os aloca seguindo uma lógica subordinada a um mercado e a um centro difusor externo. Lógica mercantil atraída por recursos raros e por possibilidades de produções complementares de alto valor nas trocas internacionais. $\mathrm{O}$ povoamento, a instalação de equipamentos, a fixação de valor, tudo responde a esta lógica, até o momento em que o volume do capital internalizado começa a gerar interesses locais, que podem se antagonizar ou não com os da metrópole, ao sabor das conjunturas. A partir desse momento, a condição subordinada passa a conviver com estímulos autocentrados, abrindo a possibilidade da colonização interna agregar mais interesses que o intercâmbio metropolitano.

Esta dinâmica interior das formações coloniais pode ser mapeada através dos circuitos internos de produção e dos círculos de cooperação que se estabele$\mathrm{cem}^{21}$. São eles as expressões e fundamentos dos interesses locais. As especializações complementares dos variados lugares, dentro de uma dada divisão regional do trabalho, revela certa maturidade desse processo, que advém da perenização de alguns fluxos. Aqui, resta muito a pesquisar, no que tange às realidades co- loniais latino-americanas. A dependência externa em muito obscureceu estes ativos circuitos internos, e é rastreando-os que podemos captar a agregação de interesses nos movimentos de emancipação política, que desenham as fronteiras nacionais dos vários países do subcontinente.

E mais, o advento da emancipação política das várias colônias não rompe, antes recicla reiterando, a centralidade da dimensão espacial na análise da América Latina. O móvel da conquista territorial permanece ativo, exercitando-se sobre lugares, recursos naturais e populações. Em primeiro lugar, o fundo territorial ainda não explorado pela economia (agora) nacional permanece a espera de novas ações, o que recoloca a noção de conquista no centro da estruturação das novas nações; inclusive dando alguns traços comuns à constituição dos respectivos aparelhos de Estado, com destaque para um forte caráter cêntrico ${ }^{22}$. Também as formas compulsórias de extração do trabalho, em geral, se mantém. Nesse sentido, a ruptura com a estruturação colonial interna pouco se exercita - expressando com clareza as qualidades de processos de modernização conservadora.

Aqui trabalhamos a hipótese de que os movimentos de independência, antes que uma superação, representaram um reforço na centralidade da dimensão espacial própria às estruturas coloniais. Pois ao lado da reposição das determinações dadas por tais estruturas (aqui sintetizadas na noção de conquista) a construção das novas identidades nacionais agrega uma outra classe de questōes importando à relação sociedade espaço. Tratam-se de questões atinentes a consciência e a representação do espaço, que associam o território ao imaginário político e aos processos de autolegitimação necessários para afirmar a soberania dos novos Esta$\operatorname{dos}^{23}$. Sim, nos países de passado colonial a idéia do na-

(21) Sobre estes conceitos ver: Antonio Carlos Robert Moraes - "Circuitos Espaciales de la produción y Circulos de Cooperación en el Espacio". Consultar também: Carlos S. Assadourian - El Sistema de la Economia Colonial. El Mercado Interior, Regiones y Espacio Económico e Juan Carlos Garavaglia - Mercado Interno y Economia Colonial.

(22) Ver: Claudio Veliz - La Tradición Centralista de América Latina e Orlando Peña - Estados y Territorios en América Latina y Caribe.

(23) Tratamos esta temática com mais detalhe em dois outros trabalhos: Ideologias Geográficas. Espaço, Cultura e Política no Brasil e "Notas sobre Identidade Nacional e Institucionalização da Geografia no Brasil". 
cional é em muito acoplada a uma visão territorial, que pode ser ilustrada numa temática recorrente na discussão de suas elites: a do país a se construir. Assim, às determinações especificamente econômicas (referentes à ocupação do solo e sua exploração) vem se juntar outras das esferas da política e da cultura.

O processo de independência do Brasil ilustra exemplarmente esse tópico. $\mathrm{O}$ compromisso em torno do príncipe português, agregando elites circunscritas a sistemas econômicos regionais, com poucos laços de coesão e complementariedade, em grande parte se fundamentou na legitimidade dinástica que a continuidade da casa real imprimia face à soberania sobre os fundos territoriais ainda não efetivamente conquistados. Observamos aqui que o ideal da conquista numa mesma argumentação fornece um elemento de coesão das elites (o da construção do país) e uma legitimação para o Estado - que terá na ocupação do território uma de suas tarefas básicas. E ainda abre a possibilidade de, no mesmo argumento, colocar o povo em seu devido lugar - qual seja, o de subalterno - isto é, mero instrumento do "projeto nacional". Não seria difícil mostrar a persistência dessa visão ao longo do período monárquico ou mesmo no Brasil republicano ${ }^{24}$.
Essa visão de conceber o país como um espaço, vendo a população como um atributo deste, não parece ser uma singularidade da formação brasileira. Ao nosso ver, ela expressaria uma qualidade das "vias" coloniais de desenvolvimento do capitalismo. Um passeio pelo pensamento conservador latinoamericano, sem dúvida, evidenciaria o peso das ideologias geográficas nas distintas formações e em diferentes conjunturas. Um exame da formação dos vários Estados permitiria avaliar o papel desempenhado pelas políticas territoriais na armação de cada um ${ }^{25}$.

\section{RESUMO}

O texto busca salientar o papel desempenhado pelas relaçóes entre a sociedade e o espaço na história latinoamericana, onde os atuais países se originam de processos de conquista territorial, isto é, desdobram-se de uma formação colonial. Tal determinação de origem perpetua-se em sociedades que tem na conquista do solo um dos seus vetores de estruturação, em certo sentido até os dias atuais. Uma exemplificaçăo de tal centralidade é đada com um esboço de análise da formaçāo estatal do Brasil, onde o componente da conquista territorial jogou e vem jogando um papel de destaque.

\section{BIBLIOGRAFIA}

ANDERSON, Perry - Linhagens do Estado Absolutista, Ed. Afrontamento, Porto, 1984.

ASSADOURIAN, Carlos Semplat - El Sistema de la Economia Colonial. El Mercado Interior, Regiones y Espacio Económico, Ed. Nueva Imagen, México, 1983.

BARBOSA-RAMIRES, René - La Estructura Económica de La Nueva Espana, Ed. Siglo Veintiuno, México, 9a. ed. 1985.

BENNASSAR, Bartolomé - La América Espanola y la América Portuguesa, Siglos XVI-XVIII, Ed. Akal, Barcelona, 1980.

CASTRO, Antonio Barros de - "As Mãos e os Pés do Senhor de Engenho: A Dinâmica do Escravismo Colonial" in Paulo Sergio PINHEIRO (org.) - Trabalho Escravo: Economia e Sociedade, Ed. Paz e Terra, Rio de Janeiro, 1983.

CHAUNU, Pierre - Conquista e Exploração dos Novos Mundos (Século XVI), Ed. Pioneira, EDUSP, São Paulo, 1984.

COSTA, Wanderley Messias da - "O Espaço como Categoria de Análise" Revista do Departamento de Geografia 3, USP, 1984.

DONGHI, Tulio Halperin - Una Nación para el Desierto Argentino, Centro Editor de América Latina, Buenos Aires, 1992.

FLORESCANO, Enrique (org.) - Haciendas, Latifundios y Plantaciones en América Latina, Ed. Siglo Veintiuno, México, 1978.
GARAVAGLIA, Juan Carlos - Mercado Interno y Economía Colonial, Ed. Grijalbo, México, 1983.

HIRANO, Sedi - Pré-capitalismo e Capitalismo, Ed. Hucitec, São Paulo, 1988.

HOBSBAWM, Eric - "A Crise Geral da Economia Européia no Século XVII" in Theo SANTIAGO (org.) - Capitalismo, Transição, Ed. Eldorado, Rio de Janeiro, 1975.

JARA, Alvaro (org.) - Tierras Nuevas, Expansión Territorial y Ocupación del Suelo en América (Siglos XVI-XIX), Ed. El Colegio de México, 1969.

KRIEDTE, Peter - Feudalismo Tardío y Capital Mercantil, Ed. Crítica, Barcelona, 1987.

LAFAYE, Jacques - Los Conquistadores, Ed. Siglo Veintiuno, México, 6a. ed. 1987.

(24) Ver, por exemplo: Ilmar Rohloff de Mattos - O Tempo Saquarema. A Formação do Estado Imperial e Lucia Lippi de Oliveira - A Questảo Nacional na Primeira República.

(25) Apenas para animar remetemos o leitor para o sugestivo trabalho de Túlio H. Donghi sobre a formação da Argentina: Una Nación para el Desierto Argentino. 
LOSADA, Mariano Useche - El Proceso Colonial en el Alto Orinoco-Rio Negro (siglos XVI-XVIII), Ed. Fundación de Investigaciones Arqueológicas, Bogotá, 1987.

MATTOS, Ilmar Rohloff - O Tempo Saquarema. A Formação do Estado Imperial, Ed. Hucitec. São Paulo, 2a. ed. 1990.

MORAES, Antonio C. R. - "Los Circuitos Espaciales de la Producción y los Círculos de Cooperación en el Espacio" in L. A. JANES e A. LIBERALLI (orgs.) - Aportes para el Estudio del Espacio Socio Económico, Ed. El Coloquio, Buenos Aires, 1989.

Ideologias Geográficas. Espaço, Cultura e Política no Brasil, Ed. Hucitec, São Paulo, 1988.

. "Notas sobre Identidade Nacional e Institucionalização da Geografia no Brasil" in Estudos Históricos 7, Rio de Janeiro, 1991.

Bases da Formação Territorial de Brasil. O Território Colonial Brasileiro no "Longo" Século XVI, Tese de Doutorado, FFLCH/USP, edição do autor, 1991.

MORAES, Antonio C. R. e COSTA, Wanderley M. - Geografia Crítica: A Valorização do Espaço, Ed. Hucitec, Sảo Paulo, 1984.

NOVAIS, Fernando A. - "Colonização e Sistema Colonial: Discussão de Conceitos e Perspectiva Histórica" in Anais do $4^{\circ}$ Encontro de Professores Universitários de História, São Paulo, 1967.
OLIVEIRA, Lucia Lippi - A Questáo Nacional na Primeira República, Ed. Brasiliense, São Paulo, 1990.

PENA, Orlando - Estados y Territorios en América Latina y el Caribe, Ed. Era, México, 1989.

ROMANO, Ruggiero - Os Mecanismos da Conquista Colonial, Ed. Perspectiva, São Paulo, 1973.

SANTOS, Milton - Por uma Geografia Nova, Ed. Hucitec, São Paulo, 1978.

"Relações Espaço-Temporais no Mundo Subdesenvolvido", Seleçăo de Textos 1, A.G.B., São Paulo, 1976.

Sociedade e Espaço, Ensaios, Ed. Vozes, Petrópolis, 1979.

VELIZ, Claudio - La Tradición Centralista de América Latina, Ed. Ariel, Barcelona, 1984.

VILAR, Pierre - Ouro e Moeda na História (1450-1920), Ed. Paz e Terra, Rio de Janeiro, 1981.

WALLERSTEIN, Immanuel - El Moderno Sistema Mundial, Ed. Siglo Veintiuno, México, 4a. ed. 1987. 